\title{
Parents and general practitioners differed in some of their views of child hyperactivity
}

Klasen H, Goodman R. Parents and GPs at cross-purposes over hyperactivity: a qualitative study of possible barriers to treatment.BrJ Gen Pract 2000 Mar;50:199-202.

\section{QUESTION: How do parents of children with hyperactivity and general practitioners (GPs) perceive hyperactivity and each other?}

Design
Grounded hermeneutic theory.

Setting

London, UK.

\section{Participants}

A purposive sample of parents of 29 children with hyperactivity ( 10 from a tertiary psychiatric referral centre, 10 from a hyperactivity support group that emphasised diet and complementary medicine, and 9 from community services) and 10 GPs in central London surgeries. $83 \%$ of children had been diagnosed as having hyperactivity; the inclusion criterion was the parental belief that their child was hyperactive.

\section{Methods}

Parents and GPs were interviewed separately about their views on hyperactivity. They were also asked about their perceptions of GPs' views and vice versa. Interviews were audiotaped and transcribed, and data were analysed by using grounded hermeneutic research procedures.

\section{Main findings}

The first theme was the difference between parents' and GPs' views of hyperactivity as a medical disorder. Parents tended to see hyperactivity as a medical rather than a psychological problem and felt blamed or dismissed by GPs who did not view hyperactivity as a medical disorder. The second theme was the effect of labelling. Parents found that a diagnosis of hyperactivity was helpful because it relieved them of a sense of guilt and provided them with the help they needed. Most GPs, however, thought that labelling hyperactive children did more harm than good. They also thought that parents' views of hyperactivity as a medical problem was a way of avoiding possible shortcomings in parenting. A third theme referred to the role of family dysfunction in hyperactivity and whether it was a cause or effect of the child's hyperactivity. Parents and GPs recognised that hyperactivity was often associated with family or social stresses. GPs tended to view family problems as a cause of problem behaviour or of parents' inability to cope with boisterous behaviour. Parents tended to view family problems (eg, sleep deprivation, social isolation, marital problems, depression, anxiety, and anger) as effects of the child's hyperactive behaviour. Other common themes emerged: (1) hyperactivity often began in the preschool years and specialist help was lacking for this age group. Parents often first approached GPs for help in the preschool years, and GPs were not aware of specialist help available for hyperactive school age children. (2) Information on hyperactivity in many information sources was conflicting and ambiguous. Parents thought that GPs were badly informed, and GPs felt they had not had sufficient training in the assessment and treatment of hyperactivity. (3) GPs and parents felt that they lacked the specialist backup services they needed. Time between first consultation with GP and diagnosis ranged from 9 months to 5 years.

\section{Conclusion}

Parents of hyperactive children and GPs differed on some views about hyperactivity, but they held common views that specialist help and backup services were lacking and that information on hyperactivity was conflicting and ambiguous.

\section{COMMENTARY}

Readers more used to quantitative research will find the study by Klasen and Goodman unusual because they report little data, do no statistical analyses, and extol the virtue of apparent bias in their methodology. What contribution does this study make?

A large North American study has shown the effectiveness of current treatments for attention deficit hyperactivity disorder (ADHD). ${ }^{1}$ Yet some children with ADHD receive treatment while others do not. ${ }^{2}$ Referral depends on recognition of needs by key adults. Evidence exists that this is substantially influenced by the burden they experience because of their children's problems. ${ }^{34}$ Adults have orientations and explanatory models that influence their interactions with professionals. This study shows how these dynamic phenomena occur.

The authors used hermeneutic research methods in which the content of events, narratives, and attitudes are studied in order to generate plausible and generalisable interpretations. Issues such as the themes found in this study can have profound effects on expectations, service uptake, and Aristotelian professional phronesis (practical wisdom), making them as important as professional techne or skills. Evidence-based practice and evidence-based service design require technical and practical wisdom. ${ }^{5}$ This study is not important for new insights into the nature of hyperactivity per se. But it highlights the importance of GPs' and parents' experiences, which may influence access to treatment for children with ADHD.

Richard Williams, MB, FRCPsych, FRCPCH, MHSM University of Glamorgan, Glamorgan, South Wales, UK

1 The MTA Cooperative Group. A 14-month randomized clinical trial of treatment strategies for attention-deficit/ hyperactivity disorder. Multimodal treatment study of children with ADHD. Arch Gen Psychiatry 1999;56;1073-86.

2 Rawlinson S, Williams R. The primary-secondary care interface in child and adolescent mental health services-burden as a defining feature. Current Opinion in Psychiatry 2000;13:389-95.

3 Wu P, Hoven CW, Bird HR, et al. Depressive and disruptive disorders and mental health service utilization in children and adolescents. I Am Acad Child Adolesc Psychiatry 1999;38:1081-90.

4 Angold A, Messer SC, Stangl D, et al. Perceived parental burden and service use for child and adolescent psychiatric disorders. Am J Public Health 1998;88:75-80.

5 Downie RS, Macnaughton J, Randall F. Clinical judgement:evidence in practice. Oxford: Oxford University Press, 2000.
Psychiatry, Institute of

SE5 8AF, UK. Fax +44

(0)2077085800. 